\title{
Evaluation of rainfall retrievals from SEVIRI reflectances over West Africa using TRMM-PR and CMORPH
}

\author{
E. L. A. Wolters ${ }^{1}$, B. J. J. M. van den Hurk ${ }^{1,2}$, and R. A. Roebeling ${ }^{1}$ \\ ${ }^{1}$ Royal Netherlands Meteorological Institute (KNMI), P.O. Box 201, 3730 AE De Bilt, The Netherlands \\ ${ }^{2}$ Institute for Marine and Atmospheric Research Utrecht (IMAU), Utrecht University, P.O. Box 80000, 3508 TA Utrecht, \\ The Netherlands
}

Received: 22 July 2010 - Published in Hydrol. Earth Syst. Sci. Discuss.: 27 August 2010

Revised: 26 January 2011 - Accepted: 31 January 2011 - Published: 3 February 2011

\begin{abstract}
This paper describes the evaluation of the KNMI Cloud Physical Properties - Precipitation Properties (CPPPP) algorithm over West Africa. The algorithm combines condensed water path (CWP), cloud phase $(\mathrm{CPH})$, cloud particle effective radius $\left(r_{\mathrm{e}}\right)$, and cloud-top temperature (CTT) retrievals from visible, near-infrared and thermal infrared observations of the Spinning Enhanced Visible and Infrared Imager (SEVIRI) onboard the Meteosat Second Generation (MSG) satellites to estimate rain occurrence frequency and rain rate. For the 2005 and 2006 monsoon seasons, it is investigated whether the CPP-PP algorithm is capable of retrieving rain occurrence frequency and rain rate over West Africa with sufficient accuracy, using Tropical Monsoon Measurement Mission Precipitation Radar (TRMM-PR) as reference. As a second goal, it is assessed whether SEVIRI is capable of monitoring the seasonal and daytime evolution of rainfall during the West African monsoon (WAM), using Climate Prediction Center Morphing Technique (CMORPH) rainfall observations. The SEVIRI-detected rainfall area agrees well with TRMM-PR, with the areal extent of rainfall by SEVIRI being $\sim 10 \%$ larger than from TRMM-PR. The mean retrieved rain rate from CPP-PP is about $8 \%$ higher than from TRMM-PR. Examination of the TRMM-PR and CPPPP cumulative frequency distributions revealed that differences between CPP-PP and TRMM-PR are generally within $+/-10 \%$. Relative to the AMMA rain gauge observations, CPP-PP shows very good agreement up to $5 \mathrm{~mm} \mathrm{~h}^{-1}$. However, at higher rain rates $\left(5-16 \mathrm{~mm} \mathrm{~h}^{-1}\right)$ CPP-PP overestimates compared to the rain gauges. With respect to the second goal of this paper, it was shown that both the accumulated precipitation and the seasonal progression of rainfall throughout the WAM is in good agreement with CMORPH, although CPP-PP retrieves higher amounts in the coastal re-
\end{abstract}

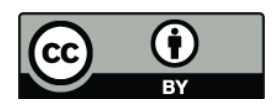

Correspondence to: E. L. A. Wolters (wolterse@knmi.nl) gion of West Africa. Using latitudinal Hovmüller diagrams, a fair correspondence between CPP-PP and CMORPH was found, which is reflected by high correlation coefficients $(\sim 0.7)$ for both rain rate and rain occurrence frequency. The daytime cycle of rainfall from CPP-PP shows distinctly different patterns for three different regions in West Africa throughout the WAM, with a decrease in dynamical range of rainfall near the Inter Tropical Convergence Zone (ITCZ). The dynamical range as retrieved from CPP-PP is larger than that from CMORPH. It is suggested that this results from both the better spatio-temporal resolution of SEVIRI, as well as from thermal infrared radiances being partly used by CMORPH, which likely smoothes the daytime precipitation signal, especially in case of cold anvils from convective systems. The promising results show that the CPP-PP algorithm, taking advantage of the high spatio-temporal resolution of SEVIRI, is of added value for monitoring daytime precipitation patterns in tropical areas.

\section{Introduction}

Precipitation can be considered the most crucial link between the atmosphere and the surface in weather and climate processes. Quantitative precipitation estimates at high spatial and temporal resolution are of increasing importance for water resource management, for improving the precipitation prediction scores in numerical weather prediction (NWP) models, and for monitoring seasonal to interannual climate variability. A dense and high-temporal resolution groundbased measurement network is required to achieve accurate precipitation observations. However, in several regions, especially over some tropical land areas and over the oceans, the coverage by rain gauges and/or ground-based radars is insufficient. For example, over certain regions in West Africa only a few rain gauges per $1000 \mathrm{~km}^{2}$ are available (Ali et al., 2005). In addition, most operational rain gauges are recorded

Published by Copernicus Publications on behalf of the European Geosciences Union. 
at daily time scales or larger. Satellite instruments, especially those onboard geostationary satellites, have the potential to provide additional insights in the spatio-temporal precipitation characteristics at sub-daily time scales. These insights are particularly useful for those regions where rain gauges are sparse.

Local economy, hydrology, and ecology in West Africa heavily depend on the availability of the monsoon rains. Especially in a region northward of $\sim 15^{\circ} \mathrm{N}$, less monsoon rain during subsequent years may intensify desertification, although no significant trend has been found throughout the 1980s and 1990s (Nicholson et al., 1998). Less rainfall during the monsoon season also results in an increased surface albedo (because of a decreased soil moisture content), increased dust generation, and less agricultural yield. Therefore continuous rainfall monitoring is of great importance.

The West African monsoon (WAM) is the northward movement of the Inter Tropical Convergence Zone (ITCZ) during boreal summer and is manifested by the convergence of moist southwesterly air from the Atlantic Ocean with dry northeasterly air from the Sahara. The start of the monsoon season is often determined by a change in sign of the zonal wind component $(u)$, i.e., a change from easterly to westerly winds. With the start of the monsoon season, first some sporadic convective activity due to the advection of moist oceanic air is triggered. This usually occurs from midApril to mid-May and is followed by a relatively dry spell of about one month. Subsequently, the full onset of the WAM sets in around the end of June. Sultan and Janicot (2003) found that this onset date is 24 June \pm 8 days for the period 1968-1990. After this onset, a band with westward moving Mesoscale Convective Systems (MCSs) traverses northward over West Africa. These MCSs partly originate in the vicinity of African Easterly Wave (AEW) troughs. The AEWs are dynamical disturbances within the African Easterly Jet (AEJ), which in turn exists due to the temperature gradient between the Gulf of Guinea and the Sahara (Cook, 1999). Fink and Reiner (2003) found that about $40 \%$ of severe MCSs over West Africa are forced through AEWs, with the percentage increasing from east to west. Further, mature large convective systems influence the AEJ through generation of a rearto-front flow in the lower part of the system and by accelerating the AEJ behind the system (Diongue et al., 2002). The initiation of MCSs is not only dynamically driven, but is also dependent on e.g. soil wetness, with convection being suppressed over soils that are too wet (Taylor and Ellis, 2006; Taylor et al., 2007).

Often a sudden shift from $\sim 5^{\circ} \mathrm{N}$ to $\sim 10^{\circ} \mathrm{N}$ of the most heavy rains is seen after the onset date. Several mechanisms explaining this monsoon jump have been proposed. For example, Sultan and Janicot (2003) suggested that due to persistent heating of the land surface near $15^{\circ} \mathrm{N}$ a thermal low develops, which is gradually strengthened by upper-air divergence caused by the Tropical Easterly Jet (TEJ). Hagos and Cook (2007) extended this view by showing through model simulations that a shallow southerly flow pattern from the Gulf of Guinea during the premonsoon phase is very important for the moisture supply into the continent. Ramel et al. (2006) debated the mechanism proposed by Sultan and Janicot (2003), as they posed that in the region near $15^{\circ} \mathrm{N}$ no sufficient low-level moisture is available to initiate largescale wet convection.

With the passage of the heavy monsoon rains, maximum convective activity occurs late in the afternoon, possibly as a result of gravity waves from morning convection over the West African ocean propagating northward (Sultan et al., 2007). However, Basu (2007) noted a shift of the main convective activity during the monsoon towards the late night/early morning, especially when dynamical factors and/or orography are involved.

The retrieval of rainfall intensity and rainfall amount from passive satellite imagery is closely related to the detection of convective cloud cells. Until now, many convection detection retrieval techniques have been developed (see e.g., Mecikalski and Bedka, 2006; Zinner et al., 2008). Most precipitation schemes from passive visible (VIS) and infrared (IR) imagery are based on the assumption that clouds start to precipitate if the thermal infrared brightness temperature (BT) becomes lower than a certain threshold value. The rationale behind this is that precipitation is more likely to occur if ice crystals are abundant in the cloud top (Pruppacher and Klett, 1997) and is generally referred to as Cold Cloud Duration technique (CCD). However, the relation between BT and rain rate is indirect, since e.g. thick cirrus clouds have low temperatures, but generally do not produce any (surfaceobserved) rain. This overestimation due to attributing rain rates to non-precipitating cirrus is partly compensated for by an underestimation of rain rates from shallow convection. Despite these drawbacks, various rainfall retrieval techniques have been based on thermal infrared (TIR) temperatures only (mostly using the 10-12 $\mu \mathrm{m}$ atmospheric window spectrum), assuming that the amount of non-precipitating cirrus clouds is only minor (Negri et al., 1984; Arkin and Meisner, 1987; Adler and Negri, 1988; Negri and Adler, 1993; Ba and Gruber, 2001). An advantage of TIR data is the availability during both day and night. Although the performance of TIRbased rainfall retrieval algorithms is quite poor in estimating instantaneous rain rates, a good correlation between cloudtop temperature and rainfall is found when accumulated over large areas and sufficiently long time periods (Kidd, 2001), although Arkin and Xie (1994) pointed out that for stratiform rain TIR-based rainfall retrievals are less accurate. Most CCD techniques are calibrated locally or regionally with rain gauge and/or passive microwave (PMW) data to obtain an optimum accuracy. See for example Huffman et al. (2001) for a detailed description of the Global Precipitation Climatology Project One-Degree Daily (GPCP-1DD) product.

More direct ways to estimate rain rate are performed by using passive microwave (PMW) data and infrared radiances. During the last decade, the development of rain rate 
retrieval algorithms has more focused on incorporating multiple sensors. For example, the Tropical Rainfall Measurement Mission (TRMM) Multi-Satellite Precipitation Algorithm (TMPA, Huffman et al., 2007) combines data from PMW imaging, sounding instruments, and geostationaryobserved IR radiances to obtain a single precipitation product. In the Climate Prediction Center Morphing Techinque (CMORPH, Joyce et al., 2004), IR radiances are used to advect/morph cloud systems between two consecutive PMW instrument overpasses to obtain intermediate rain rate estimates. A complete overview of the present-day status of the various rainfall retrieval algorithms can be found in Kidd and Levizzani (2010).

This paper presents a novel approach to estimate rain rate using retrieved cloud-top properties from visible and nearinfrared reflectances observed by the Spinning Enhanced Visible and Infrared Imager (SEVIRI) onboard the Meteosat Second Generation (MSG) satellites. The KNMI Cloud Physical Properties - Precipitation Properties algorithm (CPP-PP) differs from most state-of-the-art satellite precipitation retrieval algorithms in that it is independent of satellite data merging and calibration to rain gauge observations.

First, this paper assesses whether CPP-PP is suitable to accurately estimate rainfall over West Africa in terms of mean rainfall area and median rain rate. Earlier work already showed good performance of CPP-PP rainfall retrievals over the Netherlands in comparison with ground-based radar. The areal extent of rainfall as detected by CPP-PP from SEVIRI data correlates well (corr $\sim 0.9$ ), with the retrieved rain rates having an accuracy (defined as the difference in median rain rate between SEVIRI and rain radar) of about $11 \%$ (Roebeling and Holleman, 2009). In this paper, rainfall retrievals from the TRMM Precipitation Radar (TRMM-PR) and the CMORPH product are used as reference datasets. The CMORPH product is chosen because it is generally considered being of high quality (see e.g. Ebert et al., 2007). Although its quality is limited for convective precipitation over continental areas (Sapiano and Arkin, 2009; Jobard et al., 2010; Tian et al., 2010), the usage of almost entirely different satellite instrument data (PWM and TIR) than CPP-PP makes it a suitable alternative dataset for evaluating CPPPP. Other factors that justify using CMORPH data are the 3-hourly temporal resolution and its independency on rain gauge calibration, which enables a consistent evaluation of CPP-PP over both ocean and land surfaces.

Second, the capability of CPP-PP to monitor the progression of the monsoon rains into the West African continent and the evolution of the daytime rainfall cycle throughout the monsoon season (May-September) for three regions over the West African continent is investigated for 2005 and 2006 and compared to results obtained with CMORPH.
The paper is organized as follows. Section 2 presents the methodology and various datasets used. Section 3 contains the results and discussion, after which conclusions are drawn in Sect. 4.

\section{Data and methods}

\subsection{CPP-PP Rainfall retrieval technique}

SEVIRI, onboard the geostationary Meteosat- 8 and Meteosat-9 satellites of the European Organization for the Exploration of Meteorological Satellites (EUMETSAT), is a passive imager with 11 operational narrowband channels in the spectral range $0.6-13.4 \mu \mathrm{m}$. Three spectral channels cover the visible and near infrared, the remaining eight cover the thermal infrared spectral region. The sampling resolution is $3 \times 3 \mathrm{~km}^{2}$ at nadir. SEVIRI scans the Earth every $15 \mathrm{~min}$ from southeast to northwest.

The rainfall retrieval algorithm used here was introduced by Roebeling and Holleman (2009). It has been adapted from a method originally developed for use on the Special Sensor Microwave/Imager (SSM/I) by Wentz and Spencer (1998) to make it suitable for use on SEVIRI data. The original algorithm is only applicable to water clouds, since microwave radiation is only to a minor extent scattered by ice crystals. Therefore Roebeling and Holleman (2009) have extended the applicability to ice clouds by considering the Condensed Water Path (CWP). In other words, the CPP-PP algorithm is capable of retrieving rain rate for both stratiform ("warm" rain) and convective precipitation.

The algorithm estimates rain rate using condensed water path (CWP), cloud particle effective radius $\left(r_{\mathrm{e}}\right)$, cloud geometric height $(\Delta H)$, and cloud thermodynamic phase $(\mathrm{CPH})$ as retrieved using the Cloud Physical Properties retrieval algorithm (CPP, Roebeling et al., 2006). The algorithm is operationally applied to reflectances and radiances observed by SEVIRI.

The CPP algorithm retrieves cloud optical thickness $(\tau)$, $r_{\mathrm{e}}$, and $\mathrm{CPH}$ in an iterative way by comparing observed SEVIRI reflectances to pre-calculated lookup table (LUT) reflectances obtained from the Doubling Adding KNMI (DAK, Stammes, 2001; De Haan et al., 1987) radiative transfer model (RTM). CWP is proportional to the product of the retrieved $\tau$ and $r_{\mathrm{e}}$ values. The thermodynamic phase "water" or "ice" is assigned to those cloud flagged pixels for which the observed 0.6- and 1.6- $\mu \mathrm{m}$ reflectances match the corresponding water or ice cloud LUT reflectances. If phase "ice" is assigned, an additional CTT check (obtained from the $10.8 \mu \mathrm{m} \mathrm{BT}$ ) is applied to ascertain the cloud phase assignment. If CTT is $>265 \mathrm{~K}$, phase "ice" is changed into "water" (Wolters et al., 2008). It is noted that at low cloud fraction, $\tau$ and $r_{\mathrm{e}}$ can be significantly under- and overestimated, respectively (Wolters et al., 2010). To minimize retrieval artifacts 
resulting from low solar elevations, CPP retrievals were only performed from 07:30-16:30 UTC and limited to solar zenith angles $\left(\theta_{\circ}\right)<60^{\circ}$.

The separation of precipitating from non-precipitating clouds is the first step in the retrieval of rain rates. Precipitating clouds are detected from CWP, $r_{\mathrm{e}}$, and $\mathrm{CPH}$ information. Water cloud pixels with CWP values larger than $150 \mathrm{~g} \mathrm{~m}^{2}$ and $r_{\mathrm{e}}$ values larger than $16 \mu \mathrm{m}$ are flagged "precipitating", while for ice clouds all pixels with CWP larger than $150 \mathrm{~g} \mathrm{~m}^{2}$ are flagged "precipitating". For the pixels that are flagged "precipitating", the rain rate $\left(R\right.$, in $\left.\mathrm{mm} \mathrm{h}^{-1}\right)$ is calculated using the following equation (Roebeling and Holleman, 2009):

$R=\frac{c}{\Delta H}\left[\frac{\mathrm{CWP}_{\mathrm{a}}-\mathrm{CWP}_{\mathrm{o}}}{\mathrm{CWP}_{\mathrm{o}}}\right]^{1.6}$,

with $\mathrm{CWP}_{\mathrm{a}}$ the actual condensed water path. $\mathrm{CWP}_{\mathrm{o}}$ is an offset CWP value that is set at $125 \mathrm{~g} \mathrm{~m}^{-2}$, the constant factor $c$ has a value of 1 and is of unity $\mathrm{mm} \mathrm{h}^{-1} \mathrm{~km}$, and $\Delta H$ is the height of the rain column (in $\mathrm{km}$ ), which is defined as:

$\Delta H=\frac{\mathrm{CTT}_{\mathrm{m}}-\mathrm{CTT}_{\mathrm{a}}}{\gamma}+d H$,

in which $\mathrm{CTT}_{\mathrm{a}}$ and $\mathrm{CTT}_{\mathrm{m}}$ denote the CTT of the actual pixel and the maximum CTT in a $100 \times 100$ pixel area around the actual pixel, respectively. The pixel with maximum CTT is assumed to represent a low, thin cloud and thus gives an estimate of the cloud base. The denominator $\gamma$ represents the mean adiabatic lapse rate of $6.0 \mathrm{~K} \mathrm{~km}^{-1}$ and $d H$ represents the minimum height of the raining column in $\mathrm{km}$, which is currently set at $600 \mathrm{~m}$. At the nominal SEVIRI resolution, the minimum rain rate to be retrieved is dependent on $\Delta H$, but is generally in the order of $0.05 \mathrm{~mm} \mathrm{~h}^{-1}$. The maximum rain rate is currently set at $40 \mathrm{~mm} \mathrm{~h}^{-1}$.

\subsection{Rainfall retrieval from TRMM Precipitation Radar}

TRMM is a Low-Earth Orbiting (LEO) satellite that flies at an altitude of about $400 \mathrm{~km}$ and covers the latitudinal range between $\sim 37^{\circ} \mathrm{S}$ and $\sim 37^{\circ} \mathrm{N}$. The onboard Precipitation Radar (PR) is the first dedicated active precipitation measuring instrument launched into space. The PR obtains information on precipitation at a vertical and horizontal (nadir) resolution of $250 \mathrm{~m}$ and $4.3 \mathrm{~km}$, respectively. More details on the TRMM satellite and its instrument configuration can be found in Kummerow et al. (1998).

Since the PR suffers from considerable attenuation by large rain droplets, a correction algorithm has been developed and applied to the measured radar echo intensities $(Z)$. Subsequently, the corrected radar echo intensities are converted into rainfall rates $(R)$, using separate droplet size distributions for stratiform and convective precipitation, which are composed of $Z-R$ relations measured during aircraft campaigns at various locations around the world (Iguchi et al., 2000). In this research, the near-surface observed precipitation from the TRMM PR 2A25 (version 6) product is used. The $2 \mathrm{~A} 25$ product has been validated over West Africa using rain gauge measurements for the 1998 monsoon season (Nicholson et al., 2003) and over Florida using ground-based rain radar (Liao and Meneghini, 2009). In the former study, it was found that the seasonally averaged bias of TRMM-PR is $+0.3 \mathrm{~mm} \mathrm{~d}^{-1}$ (+7\% relative), with an RMSE of $1.9 \mathrm{~mm} \mathrm{~d}^{-1}$. In the latter study, a TRMM-PR overestimate for stratiform rain by $9 \%$ was revealed, whereas convective rainfall is underestimated by $19 \%$.

\subsection{CMORPH rainfall retrieval technique}

CMORPH is one of the recently developed rainfall retrieval techniques which synergize LEO-observed PMW data with geostationary-observed TIR data. At present, the PMW rain rates are obtained from the Advanced Microwave Sounder Unit-B (AMSU-B), SSM/I, and the TRMM Microwave Imager (TMI). For the three PMW sensors, separate rainfall retrieval algorithms are used. However, to account for the different channel characteristics of AMSU-B its rainfall retrievals are normalized to those of SSM/I and TMI using a histogram matching technique. See Joyce et al. (2004) and references therein for more details on the PMW channel characteristics and normalization procedure.

Thermal infrared radiances from five geostationary satellites [the two Geostationary Operational Environmental Satellites (GOES), Meteosat-9, Meteosat-5, and the Geostationary Meteorological Satellite 5 (GMS-5)] are parallaxcorrected and mapped to a 4-km grid at a temporal resolution of $30 \mathrm{~min}$. Subsequently, these TIR data are used to calculate cloud motion vectors. For the observational gaps between two PMW instrument overpasses, the observed raining systems are propagated both forward and backward in time using the motion vectors. Finally, the forward and backward propagated rainfall is inversely weighted with the respective temporal distance from the initial and subsequent PMW instrument observations to obtain a change in intensity and shape of the precipitation systems. In this study, the 3-hourly $0.25^{\circ} \times 0.25^{\circ}$ product is used.

\subsection{Evaluation of SEVIRI rain rates}

\subsubsection{Comparison with TRMM-PR and CMORPH}

As mentioned earlier, this paper first presents an evaluation of the CPP-PP rainfall observations over West Africa through a comparison with TRMM-PR using 1) the observed areal rainfall and instantaneous rain rates of SEVIRI and TRMM-PR and 2) the SEVIRI- and TRMM-PR-observed frequency distributions of rain rate. Both comparisons have been performed for the region $0^{\circ}-20^{\circ} \mathrm{N}, 10^{\circ} \mathrm{W}-10^{\circ} \mathrm{E}$ for May-September 2005 and 2006.

For the instantaneous comparison, initially 150 TRMMPR overpasses were selected and collocated with the SEVIRI rainfall retrievals. Both SEVIRI and TRMM-PR retrievals 
were reprojected to a $0.1^{\circ} \times 0.1^{\circ}$ grid. In accordance with the TRMM-PR detection threshold of $0.5 \mathrm{~mm} \mathrm{~h}^{-1}$ (Liao and Meneghini, 2009), SEVIRI rain rate retrievals below this threshold were considered as non-precipitating.

For each TRMM-PR overpass, the SEVIRI image closest in time was selected, which gives a maximum time difference of $\sim 7 \mathrm{~min}$. An example of a collocated TRMM-PR overpass with SEVIRI is shown in Fig. 1. In order to avoid possible spatial collocation mismatches, we refrained from comparing pixel-by-pixel values. Instead, the mean rainfall area and median rain rate were calculated. The TRMM-PR and CPP$\mathrm{PP}$ areal rainfall were calculated by dividing the number of grid boxes for which the TRMM-PR-observed rain rate exceeded the $0.5 \mathrm{~mm} \mathrm{~h}^{-1}$ detection threshold to the total number of grid boxes in a TRMM-PR overpass. In 23 overpasses, no rain was detected, so 127 TRMM-PR overpasses were included in the comparison dataset.

Additional to the comparison of SEVIRI- and TRMMPR-derived rain rates per overpass, the relative and cumulative frequency distributions were computed for daytime TRMM-PR and SEVIRI rain retrievals at $0.1^{\circ} \times 0.1^{\circ}$ with rain rate exceeding $0.5 \mathrm{~mm} \mathrm{~h}^{-1}$. Subsequently, a bootstrapping technique was applied to obtain an indication on the uncertainty of the obtained cumulative distribution functions. Using this bootstrapping technique, from the original cumulative frequency distribution consisting of about 14000 retrievals 10000 new cumulative frequency distributions were computed by randomly drawing values from the original observations.

\subsubsection{Comparison with rain gauge observations}

Rain gauge observations from 110 stations operated within the framework of the African Monsoon Multidisciplinary Analysis project (AMMA, Redelsperger et al., 2006) were used as a third evaluation dataset. Since satellite and groundbased rainfall observations are difficult to compare in terms of time series or on a pixel-by-pixel basis (areal averages observed from satellite versus point measurements from rain gauges), the rain gauge observations were only included in the comparison of the relative and cumulative frequency distributions. The stations were selected from the Gourma, Kori de Dantiandou, Niamey, and Ouémé mesoscale sites. Figure 2 shows the location of the rain gauges. The majority of the rain gauge stations were operated during the monsoon seasons of 2005 and 2006.

Precipitation at these stations is recorded at a 5-min resolution. Note that a different part of a cloud is sampled by rain gauges and satellites. Satellite instruments observe an areaaveraged rain rate of an instantaneous observation, while rain gauges sample rain rate over a period of time at one location. It is assumed that rain gauge observations taken over a period of time represent a transect through a cloud system. To minimize the sampling and collocation uncertainties one needs to apply a correction procedure. In our pa-

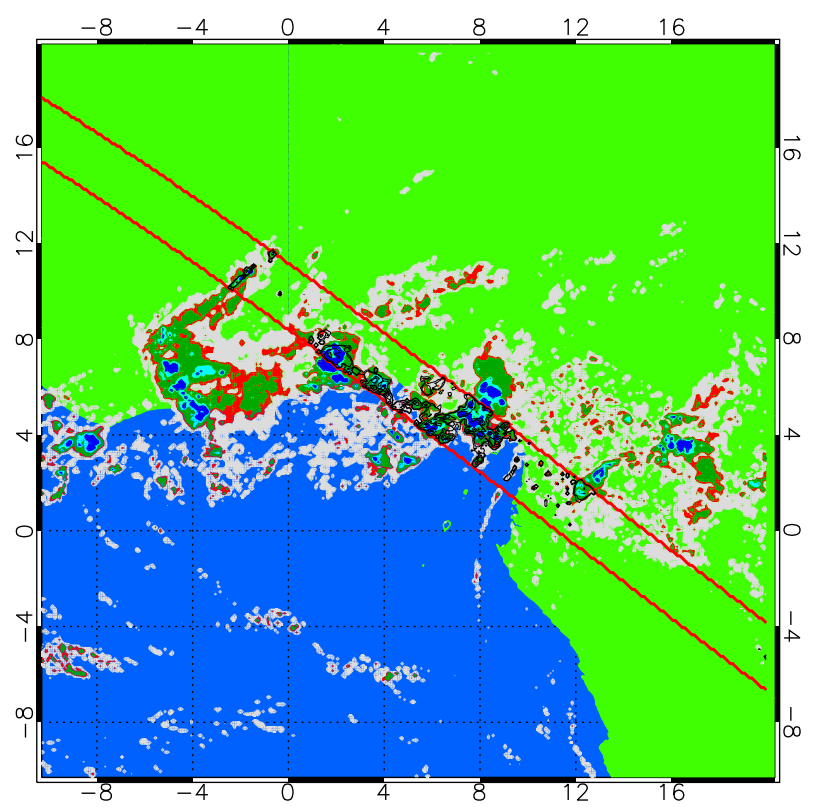

Fig. 1. Example of a collocated SEVIRI image with a TRMM-PR overpass over the Guinean coastal area at 16 May 2006, 11:15 UTC. SEVIRI rain rates are in color-filled contours, while TRMM-PR rain rates are indicated by open contours. Countour intervals are drawn at $0.1,0.5,1,5$, and $10 \mathrm{~mm} \mathrm{~h}^{-1}$. The red lines indicate the edges of the TRMM-PR swath.

per we assumed that a cloud system remains constant over the time period between two consecutive SEVIRI images, the averaging period of the surface observations to match the satellite pixel size is mostly a function of wind speed and wind direction. Correction procedures and their underlying assumptions to make possible a proper comparison between satellite retrievals and ground-based observations are described by Greuell and Roebeling (2009) and Schutgens and Roebeling (2009) for Liquid Water Path (LWP). However, it is noted that precipitation is of a more intermittent nature than LWP, hence the above described correction procedure would necessitate various corrections. Therefore it was chosen to simply aggregate over 15 minutes centered at the SEVIRI observation times to approximate the $0.1^{\circ} \times 0.1^{\circ}$ satellite grid boxes that were used to construct the frequency distributions. In order to preserve as closely as possible the same rainfall characteristics as observed by the satellite rainfall retrieval techniques, only daytime rain gauge measurements were included (07:30-16:30 UTC). The relative and cumulative frequency distributions were constructed by collecting all 15 -min observations with rain rates $>0.5 \mathrm{~mm} \mathrm{~h}^{-1}$ into $0.01 \mathrm{~mm} \mathrm{~h}^{-1}$ wide bins. 


\subsection{Evaluation of the monsoon progression over West Africa}

In addition to the verification of the CPP-PP rain rate accuracy, the detection of the WAM rainfall progression on seasonal and sub-daily time scale is of interest. To investigate the ability of CPP-PP to monitor the seasonal monsoon scale, latitudinal Hovmüller diagrams were constructed for rain occurrence frequency and rain rate for the monsoon seasons of 2005 and 2006. In these periods, three data gaps in our SEVIRI data archive occurred (1-8 August 2005, 17 August 2006, and 24-30 September 2006), but still about $90 \%$ of the total number of daytime observations were available. The latitudinal Hovmüller diagrams were constructed from the $0.25^{\circ} \times 0.25^{\circ}$ SEVIRI and CMORPH observations.

First, all SEVIRI images were aggregated to a $0.25^{\circ} \times 0.25^{\circ}$ grid. Subsequently, for each SEVIRI image and each $0.25^{\circ} \times 0.25^{\circ}$ latitude grid box all retrievals with solar zenith angles less than $60^{\circ}$ and rain rate larger than $0.05 \mathrm{~mm} \mathrm{~h}^{-1}$ were averaged over $10^{\circ} \mathrm{W}-10^{\circ} \mathrm{E}$, thus yielding at maximum 80 values per image for $0^{\circ}-20^{\circ} \mathrm{N}$. Subsequently, all values per latitude were averaged with the number of images per day. The same was done using CMORPH data collected at 09:00, 12:00, and 15:00 UTC.

The daytime cycle of precipitation was investigated for three areas. The latitudinal bands were chosen analogously to Mohr (2004), and are primarily based on vegetation type: $7^{\circ}-10^{\circ} \mathrm{N}$ (rain forest), $10^{\circ}-15^{\circ} \mathrm{N}$ (savannah), and $15^{\circ}-$ $20^{\circ} \mathrm{N}$ (semi-desert). For clarity, these areas are indicated in Fig. 2. Within these areas, for May-September of 2005 and 2006 all 15-min regridded CPP-PP retrievals having $R>0.05 \mathrm{~mm} \mathrm{~h}^{-1}$ were collected into hourly bins (centered at 08:00, 09:00, .., 15:00, 16:00 UTC). The solar zenith angle limit was set at $50^{\circ}$ to minimize retrieval artifacts contaminating the daytime precipitation signal. Subsequently, for each hour the 25 th, 50 th, and 75 th percentiles of rain rate were calculated.

\section{Results}

\subsection{Validation of SEVIRI rainfall retrievals with TRMM-PR}

Figure 3 presents the obtained rainfall area and median rain rate per TRMM-PR overpass from SEVIRI and TRMM-PR data. The left panel in Fig. 3 shows that the TRMM-PR and CPP-PP rainfall area agree well $($ corr $=0.86)$. However, the rainfall area retrieved by CPP-PP is about $10 \%$ larger than the area observed by TRMM-PR. This difference might be a result from differences in the rainfall observation techniques of TRMM-PR and SEVIRI or the threshold settings used to separate precipitating from non-precipitating pixels.

The scatter plot of median rain rate per TRMM-PR overpass (Fig. 3, right panel) reveals that the correlation between

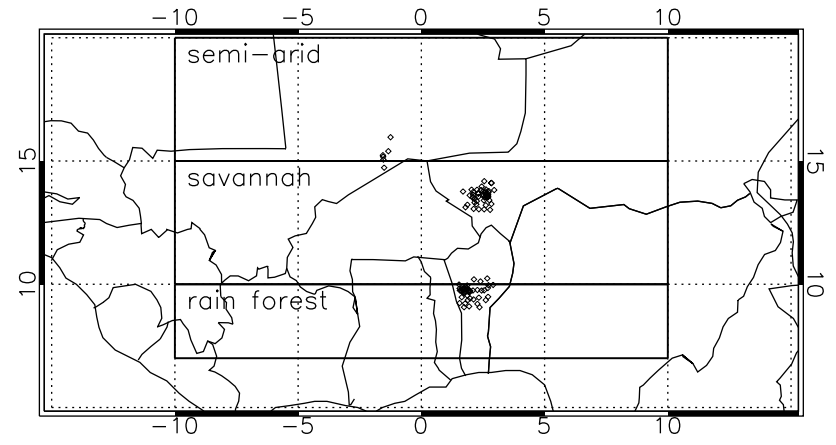

Fig. 2. Locations of the 110 selected AMMA rain gauges, which were used for the validation of the CPP-PP rain retrievals, and the three regions (designated "rain forest", "savannah", and "semiarid") used for calculating the CPP-PP and CMORPH daytime cycle.

TRMM-PR and SEVIRI is weaker than for rainfall area. Also, the dynamic range of $0-3 \mathrm{~mm} \mathrm{~h}^{-1}$ for TRMM-PR is about $75 \%$ smaller than for SEVIRI $\left(0-5 \mathrm{~mm} \mathrm{~h}^{-1}\right)$. As noted earlier, Liao and Meneghini (2009) found that TRMM-PR retrieves lower rain rates for convective systems as compared to ground-based radar observations. Part of the differences between both datasets are caused by errors due to differences in the spatial and temporal sampling. Roca et al. (2010) presented a method that corrects for such types of errors, and found that the correlation coefficient generally increases when these errors are accounted for in both datasets.

The cumulative and relative frequency distributions are presented in Fig. 4. The dotted lines indicate the respective standard deviations of the cumulative frequency per rain rate bin, which were calculated using the bootstrapping technique.

From Fig. 4, left panel, it follows that the rain rates from TRMM-PR are higher than from CPP-PP up to the 60th percentile, with relative differences being below $10 \%$. Between the 60th and 90th percentile, CPP-PP has higher rain rates than TRMM-PR by $0.5-1.0 \mathrm{~mm} \mathrm{~h}^{-1}(5-15 \%$ relative difference), although this overestimation diminishes beyond the 75th percentile. With respect to the AMMA rain gauge observations, both TRMM-PR and CPP-PP tend to overestimate rain rates.

The relative frequency distributions (Fig. 4, right panel) show that CPP-PP and TRMM-PR have a lower occurrence frequency than the rain gauges for $R<1 \mathrm{~mm} \mathrm{~h}^{-1}$. Further, CPP-PP is higher than both TRMM-PR and the rain gauges for rain rates between 5 and $\sim 16 \mathrm{~mm} \mathrm{~h}^{-1}$, but retrieves lower occurrence frequencies again for $R>\sim 20 \mathrm{~mm} \mathrm{~h}^{-1}$. The latter could be the result of an underestimation of $r_{\mathrm{e}}$. In large convective systems, fast updrafts transport smaller and lighter ice crystals to the cloud top. Since for thick convective clouds the retrieved $r_{\mathrm{e}}$ is only representative of the first optical thickness units (i.e., only the first few hundreds of 

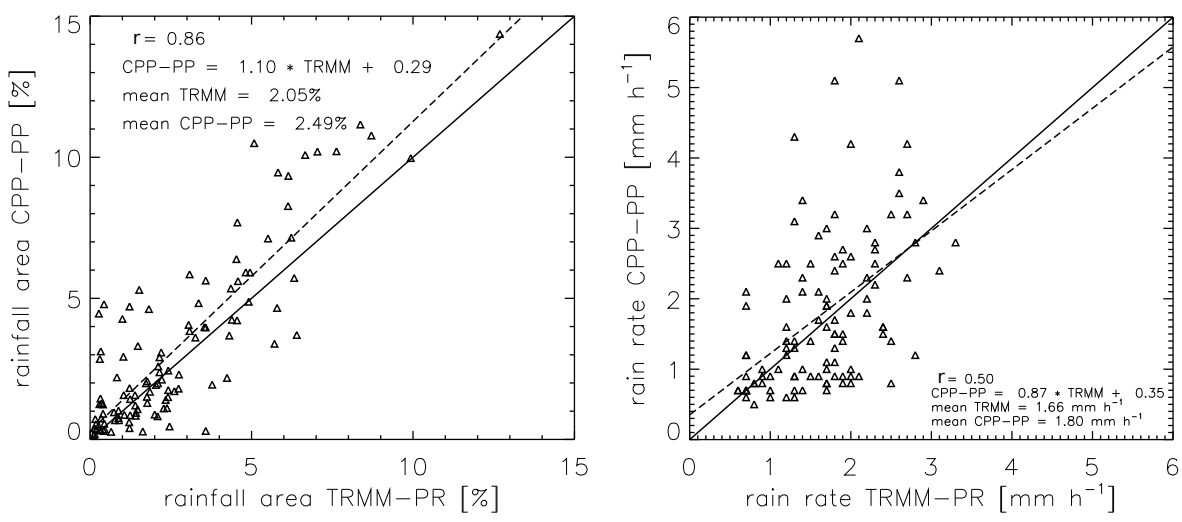

Fig. 3. (Left) detected rainfall area (in \% per TRMM-PR overpass) for retrievals with $R>0.5 \mathrm{~mm} \mathrm{~h}^{-1}$ and (right) the corresponding median rain rates per overpass as observed by TRMM-PR and SEVIRI. Solid lines indicate the 1:1 relation, dashed lines denote linear regressions.
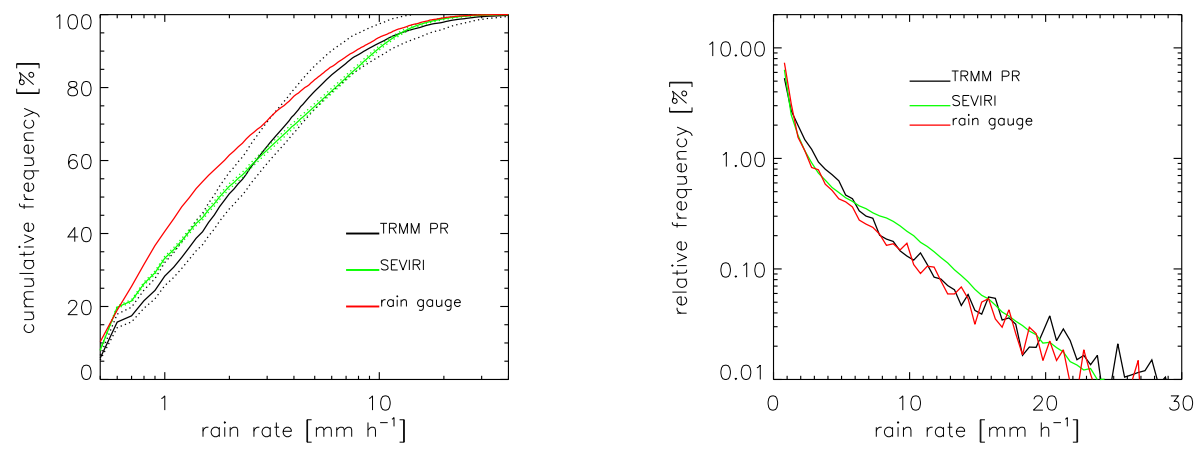

Fig. 4. (Left) cumulative frequency distribution of rain rate derived from (black) TRMM-PR, (green) SEVIRI using CPP-PP, and (red) daytime (07:30-16:30 UTC) rain gauge observations from the selected stations shown in Fig. 2. Note the logarithmic scaling on the $x$-axis. The accompanying dotted lines for TRMM-PR and SEVIRI denote the standard deviation at each rain rate bin, which was obtained from a bootstrapping technique using 10000 draws. (Right) corresponding relative frequency distribution for TRMM-PR, SEVIRI, and rain gauge with logarithmic scaling on the $y$-axis. Results are shown for $10^{\circ} \mathrm{W}-10^{\circ} \mathrm{E}, 0^{\circ}-20^{\circ} \mathrm{N}$.

meters) and no information on the ice crystal size at lower altitudes can be obtained, the column integrated condensed water path and hence rain rate could be underestimated for these types of cloud.

\subsection{Monitoring of monsoon progression}

Both the 2005 and 2006 monsoon seasons were characterized by a near-normal rainfall amount relative to the 19512000 mean (based on Global Precipitation Climatology Center (GPCC) data, Rudolf, 1993), although their development was different in terms of convection. First, the location of the ITCZ in 2005 was about $2^{\circ}$ latitude above its climatological mean throughout almost the entire monsoon season. In addition, the 2005 monsoon onset date was earlier than the average onset date, while the 2006 monsoon contrasted with an onset due by about 10 days. Finally, colder Sea Surface Temperature (SST) in 2005 compared to 2006 occurred in the Gulf of Guinea, which for the latter year resulted in a slower monsoon development due to a smaller temperature gradient between ocean and continent (Janicot et al., 2008).
To demonstrate the ability of CPP-PP to monitor the rainfall dynamics, Fig. 5 shows the mean daytime rainfall amount for May-September 2005 for $0^{\circ}-20^{\circ} \mathrm{N}, 10^{\circ} \mathrm{W}-10^{\circ} \mathrm{E}$. Since CMORPH data is only available at a $3-\mathrm{hr}$ resolution and due to CPP-PP retrievals being limited to daytime data, for both datasets only observations at 09:00, 12:00, and 15:00 UTC were included. For each month, precipitation retrievals were accumulated and converted to a mean daily precipitation, assuming a uniform distribution of rainfall throughout the day.

Figure 5 reveals that both CPP-PP and CMORPH capture the monthly shift of the monsoon rain patterns over the West African continent. In May 2005, the major rain bands are along the coastline $\left(\sim 5^{\circ} \mathrm{N}\right)$, with also some sporadic convection in a band near $10^{\circ} \mathrm{N}$. The eastward part of this band, as well as some parts of the coastal rain band are observed somewhat more prominent by CPP-PP than by CMORPH.

In June 2005, CPP-PP retrieves higher rain rates along the West African coast than CMORPH. This is particularly evident in the western part, where CMORPH partly has a mean daytime rainfall of $<3 \mathrm{~mm} \mathrm{~d}^{-1}$, while CPP-PP 

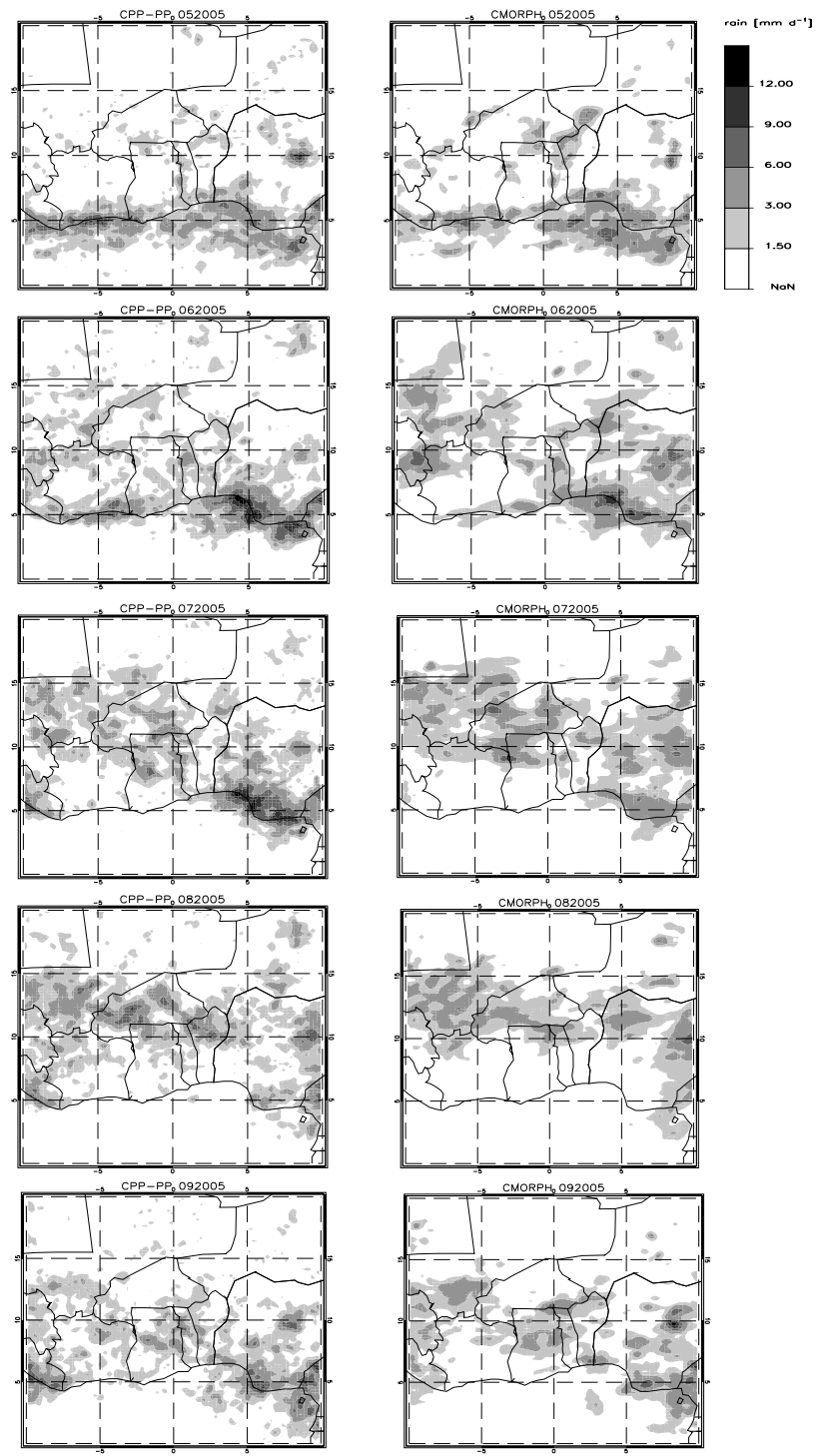

Fig. 5. Mean accumulated daily precipitation (expressed in $\mathrm{mm}$ $\mathrm{d}^{-1}$ ) for May-September 2005 from (left) CPP-PP and (right) CMORPH. For both datasets observations at 09:00, 12:00, and 15:00 UTC were included. See text for further details.

retrieves values of $3-6 \mathrm{~mm} \mathrm{~d}^{-1}$. Furthermore, the rainfall over the continent west of $0^{\circ}$ is observed as smaller scale convection by CPP-PP. This is likely the result of the coarser resolution of CMORPH. Despite the usage of geostationary IR radiances at $4 \times 4 \mathrm{~km}$, the CMORPH data resolution is limited by the relatively large PMW instrument resolution ( $\sim 10-15 \mathrm{~km}$, Joyce et al., 2004). The rapid northward movement of the major rain systems between June and July 2005 is seen by both CPP-PP and CMORPH, with both the location and intensity largely in agreement. As for May and June, CPP-PP observes more intense rains along the eastern West African coast than CMORPH, which seems to be more in agreement with the GPCC observations (not shown).
In August, the monsoon rains have reached their northernmost position and daytime rain totals are less than $3 \mathrm{~mm} \mathrm{~d}^{-1}$ along the coast. Most rain is observed in the western part of West Africa (with several areas having 6-9 $\mathrm{mm} \mathrm{d}^{-1}$ ), which may be due to initiation and/or (re)activation of MCSs/squall lines over the Aïr mountains (Mohr, 2004). In September, the monsoon rains have retreated southward and in general their intensity has decreased.

Figure 6 shows the latitudinal Hovmüller plots from CPP-PP and CMORPH daytime rainfall retrievals for MaySeptember 2005 and 2006. As in Fig. 5, the general features and seasonal march of the monsoon of CMORPH and CPP-PP agree fairly well, with the correlation coefficient of non-zero rain rates being 0.64 and 0.76 for 2005 and 2006, respectively. For both datasets and both years, the southward retreat of the monsoon rains is more pronounced than the northward movement during May-July. It is suggested that the northward displacement of the monsoon rains occurs at different speeds along the longitudes investigated $\left(10^{\circ} \mathrm{W}-\right.$ $10^{\circ} \mathrm{E}$ ). Some evidence of this can be seen in Fig. 5 for June and July 2005; the monsoon rains west of $0^{\circ} \mathrm{E}$ have reached as far as $\sim 13-15^{\circ} \mathrm{N}$, while east of $0^{\circ} \mathrm{E}$ the monsoon rains are roughly $3^{\circ}$ more southward. The slower movement east of $0^{\circ} \mathrm{E}$ is possibly due to blocking and forced convection on the windward side of the Cameroon Highlands (near $7^{\circ} \mathrm{N}$, $\left.9^{\circ} \mathrm{E}\right)$.

For 2005 (Fig. 6a and c), CPP-PP retrieves higher rain rates (up to $1.3 \mathrm{~mm} \mathrm{~h}^{-1}$, but mostly $0.2-0.4 \mathrm{~mm} \mathrm{~h}^{-1}$, not shown) than CMORPH along the coastline during June and July, a feature which is also visible in Fig. 5. The higher rain rates compared to CMORPH are compensated for by several lower rain rates (mainly over the continent, e.g. $10^{\circ}-$ $15^{\circ} \mathrm{N}$ during the first part of June), which is reflected by a mean difference CPP-PP-CMORPH of $0.0 \pm 0.16 \mathrm{~mm} \mathrm{~h}^{-1}$. In both datasets the monsoon rains reach their northernmost position at $\sim 15^{\circ}$ during late July and early August. Finally, from late August onwards the monsoon retreats southward, which is well visible in both CPP-PP and CMORPH.

The seasonal signature of the 2006 WAM (Fig. $6 \mathrm{~b}$ and d) is different from that in 2005. In both CMORPH and CPP-PP a larger latitudinal extent of the oceanic/coastal rains $(\sim 2-$ $6^{\circ} \mathrm{N}$ ) during the early monsoon (May and June) is seen. In addition, during late June and early July a decrease in the latitudinal extent of these rain bands can be seen, a feature also recognizable when precipitation is averaged over several years (Hagos and Cook, 2007). As for 2005, CPP-PP retrieves higher rain rates in the coastal area (up to $7^{\circ} \mathrm{N}$ ) than CMORPH, but the difference is larger than for 2005 , with values occasionally $>0.5 \mathrm{~mm} \mathrm{~h}^{-1}$. The mean difference is $+0.05 \pm 0.21 \mathrm{~mm} \mathrm{~h}^{-1}$. CPP-PP retrieves higher rain rates than CMORPH until around mid-July, after which the maximum precipitation shifts towards $\sim 12^{\circ} \mathrm{N}$. In $\mathrm{CMORPH}$, the monsoon jump is observed around the same date and at approximately the same location. 

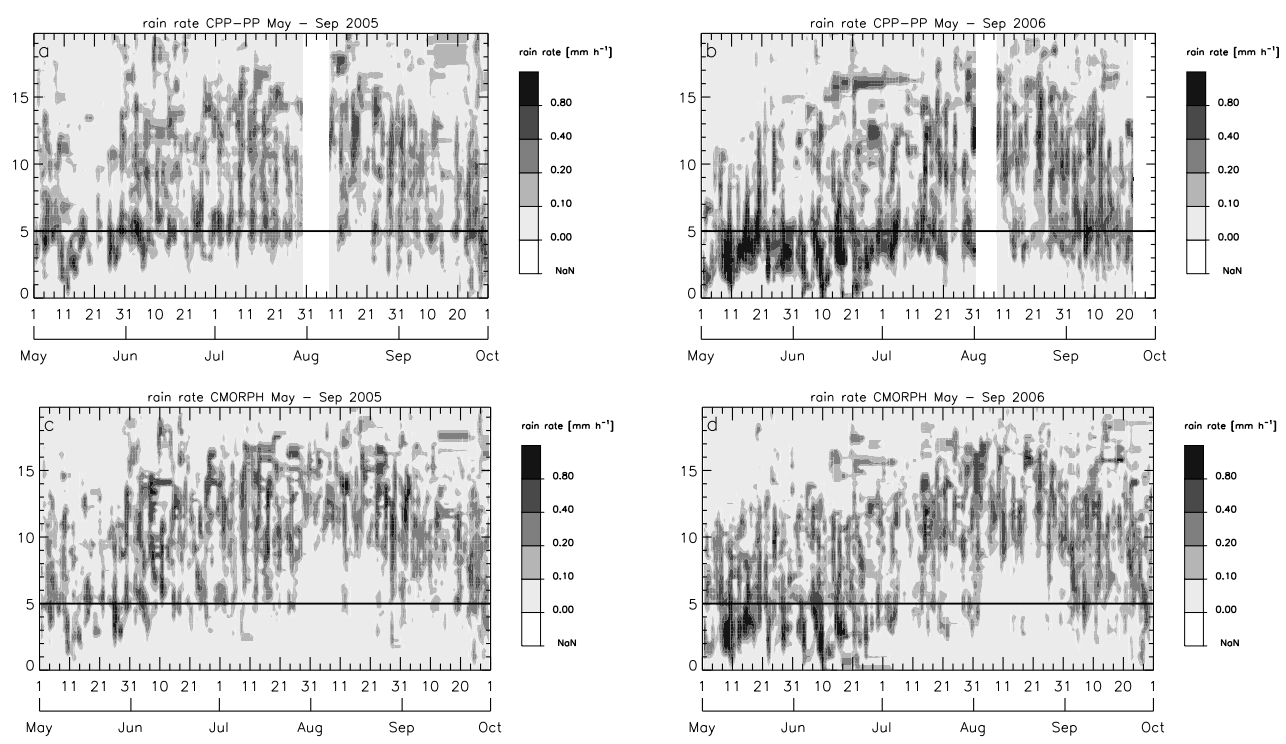

Fig. 6. Hovmüller plots of (left) 2005 and (right) 2006 daytime conditional rain rate $\left(R>0.05 \mathrm{~mm} \mathrm{~h}^{-1}\right)$ for $0^{\circ}-20^{\circ} \mathrm{N}$; (top) $\mathrm{CPP}-\mathrm{PP}$ and (bottom) CMORPH. Both datasets are at $0.25^{\circ} \times 0.25^{\circ}$ resolution. Values have been averaged over $10^{\circ} \mathrm{W}-10^{\circ} \mathrm{E}$. The thick horizontal line denotes the approximate location of the coastline. The white bands in the CPP-PP plots indicate data archive gaps.

The fair agreement between the CPP-PP and CMORPH Hovmüller plots is emphasized in Fig. 7, which shows the latitudinal cross sections of the monthly mean rain rate from CPP-PP and CMORPH for May-September 2005 and 2006. Especially over the continent $\left(>\sim 5^{\circ} \mathrm{N}\right)$, the differences between CPP-PP and CMORPH are small. Larger differences occur over the coastal/oceanic area, with the largest differences in 2006 (see also Fig. 6). It is again mentioned that CPP-PP tends to have a better agreement in the coastal areas with GPCC rainfall than CMORPH.

Figure 8 presents the 2005 and 2006 Hovmüller plots of CPP-PP- and CMORPH-retrieved rain occurrence frequency. Similar to the rain rate plots, the correlation between the two datasets is high (0.70 and 0.76 for 2005 and 2006, respectively). In addition, as for rain rate, CPP-PP retrieves a higher rain occurrence frequency in the coastal area, with overestimations up to $28 \%$. The mean difference CPP-PPCMORPH is $-0.1 \pm 6.6 \%$ and $+4.2 \pm 9.8 \%$ for 2005 and 2006, respectively.

\subsection{Daytime cycle of precipitation}

Figure 9 shows the daytime cycle of rain rate and rain occurrence frequency for CMORPH and CPP-PP over three regions (see also Fig. 2), averaged over May-September 2005 and 2006: $7^{\circ}-10^{\circ} \mathrm{N}, 10^{\circ}-15^{\circ} \mathrm{N}$, and $15^{\circ}-20^{\circ} \mathrm{N}$, with all areas having longitudinal extents $10^{\circ} \mathrm{W}-10^{\circ} \mathrm{E}$. Note that both datasets are at $0.25^{\circ} \times 0.25^{\circ}$ grid. For convenience, the regions are designated as "rain forest", "savannah", and "semidesert", respectively, consistent with the analysis of Mohr (2004). To reduce noise in the results, only rain rates larger than $0.05 \mathrm{~mm} \mathrm{~h}^{-1}$ were included.
Over the rain forest region $\left(7^{\circ}-10^{\circ} \mathrm{N}\right)$, the median rain rate shows a small decline during morning and early afternoon and slowly increases during the afternoon in May. The region is close to the monsoon rains, which probably causes the reduced dynamical range (see also the 75th percentile), as more dynamically driven convection occurs. The agreement with CMORPH is good, with a small underestimation of $\sim 0.1 \mathrm{~mm} \mathrm{~h}^{-1}$ by CPP-PP for all three percentiles shown. Note that the CPP-PP plots are at an hourly resolution, whereas those for CMORPH are given each $3 \mathrm{~h}$.

During June and July, the dynamics in daytime rainfall cycle as retrieved from CPP-PP increase as the ITCZ has passed the region; the median (75th percentile) rain rate decreases from $\sim 0.35$ (1.6) $\mathrm{mm} \mathrm{h}^{-1}$ at 08:00 UTC to $0.2(0.6) \mathrm{mm} \mathrm{h}^{-1}$ around noon, after which the rain rates increase towards the end of the CPP-PP observation period (the bin centered at 16:00 UTC). Compared to CPP-PP, CMORPH has a much weaker daytime rainfall cycle. This may be due to several factors, among others the use of TIR data to interpolate and morph rain rates between PMW instrument overpasses, which smoothes the rainfall signal. In August and September, the dynamical range in daytime rainfall as retrieved by CPP-PP decreases again slightly, as the ITCZ retreats southward and the daytime cycle of rainfall is less dominated by differential heating. This is possibly because of the occurrence of MCSs, which can be maintained throughout the night due to dynamical forcing and cloud-top radiative cooling (Dai, 2001; Yang and Smith, 2006).

Similar to the rain forest region, for the savannah and semi-desert region the dynamical range of rainfall during daytime decreases when the monsoon rain bands pass (see for example the difference between May and July for the 

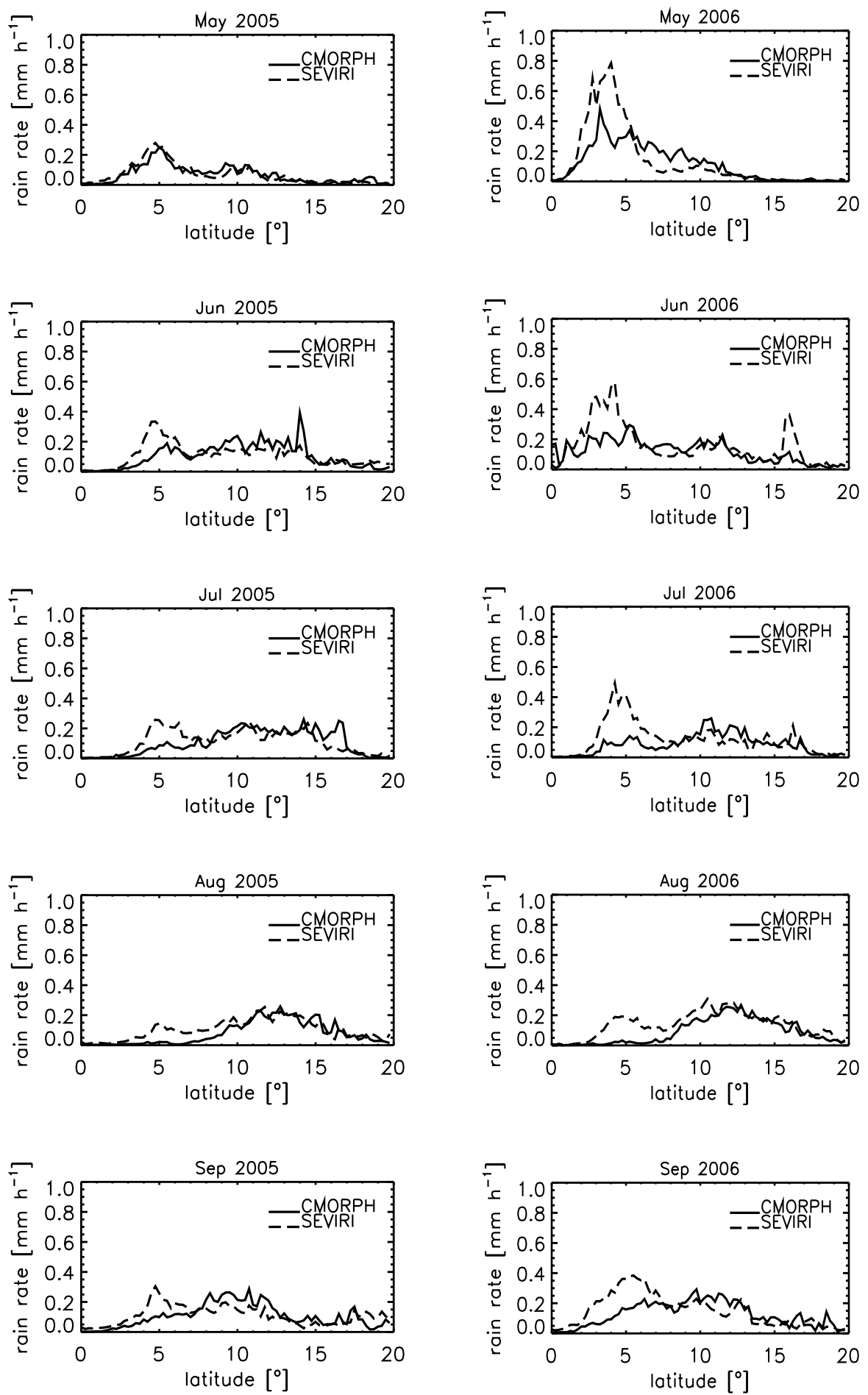

Fig. 7. Latitudinal cross section of monthly mean daytime conditional rain rate $\left(R>0.05 \mathrm{~mm} \mathrm{~h}^{-1}\right)$ from CMORPH (solid line) and CPP-PP (dashed line) for (left) May-September 2005 and (right) May-September 2006. Both datasets are at $0.25^{\circ} \times 0.25^{\circ}$ resolution.

savannah region, Fig. 9, middle column). In addition, as for the rain forest region, for almost all months CPP-PP has lower absolute rain rate values compared to CMORPH. In addition, the dynamical range of the daytime rainfall cycle is larger from CPP-PP than from CMORPH. Finally, the higher percentiles of CPP-PP have a larger amplitude than those from CMORPH. With respect to the lower rain rate values of CPP-PP relative to CMORPH over the continent, it is 

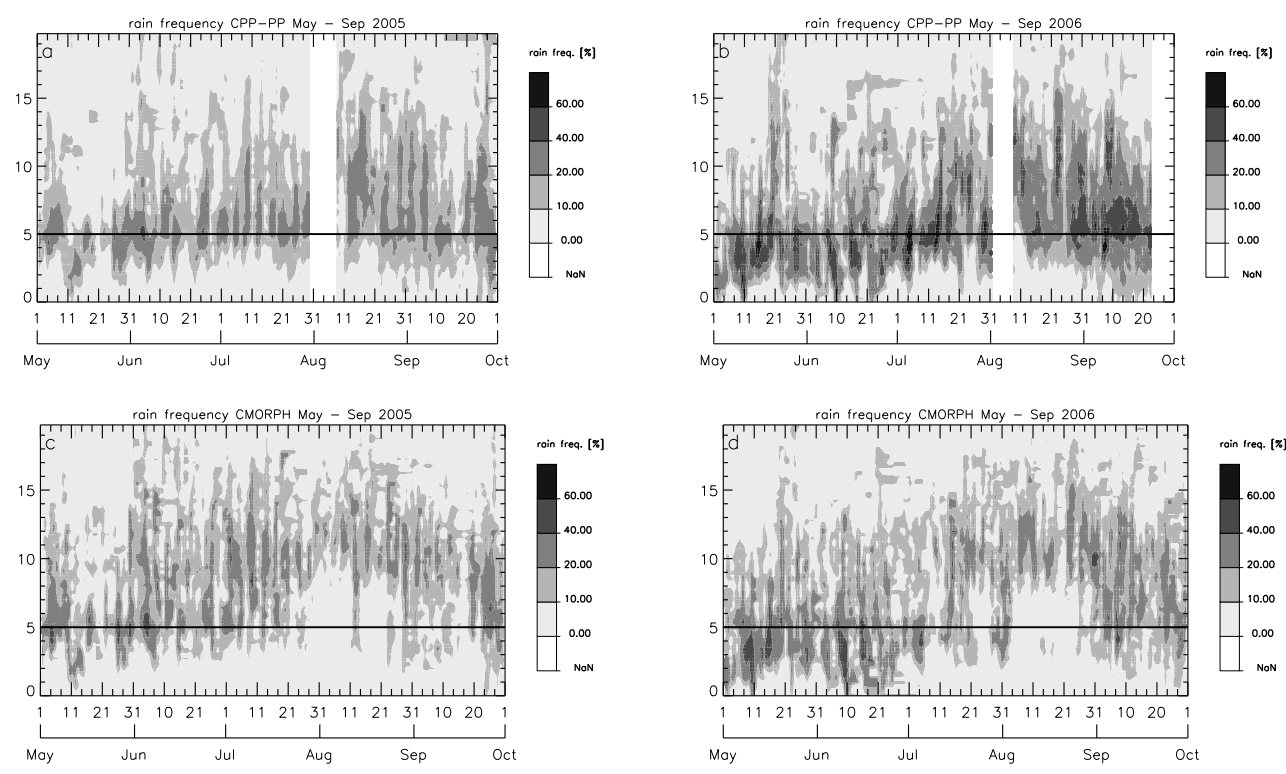

Fig. 8. As Fig. 6, but for rain ocurrence frequency.

mentioned that CMORPH tends to overestimate the rainfall over these areas (Sapiano and Arkin, 2009). Furthermore, Tian et al. (2010) found this overestimation to particularly occur during the summer season, i.e., when convective processes dominate precipitation formation.

\section{Summary and conclusions}

This paper presented the evaluation of the CPP-PP rain retrieval algorithm on SEVIRI visible and near-infrared reflectances over West Africa for May through September of 2005 and 2006. The algorithm combines retrieved cloud particle effective radius, cloud phase, and cloud-top temperature information to estimate rain rate. Instantaneous rainfall retrievals were compared against TRMM-PR and rain gauge observations. CPP-PP is well able to capture the rainfall characteristics observed by TRMM-PR; the areal rainfall retrieved by CPP-PP of $2.5 \%$ is higher than the corresponding value from TRMM-PR of $2.0 \%$, which is a satisfactory agreement given the different measurement techniques. Further, it was shown that the mean retrieved rain rate from CPP$\mathrm{PP}$ is $\approx 8 \%$ higher than from TRMM-PR.

Examination of the TRMM-PR and CPP-PP cumulative frequency distributions revealed that differences between CPP-PP and TRMM-PR are generally within +/-10\%. Relative to the AMMA rain gauge observations, CPP-PP shows very good agreement up to $5 \mathrm{~mm} \mathrm{~h}^{-1}$, however, at higher rain rates $\left(5-16 \mathrm{~mm} \mathrm{~h}^{-1}\right)$ CPP-PP overestimates compared to the rain gauges.

A second goal of the paper was to demonstrate to which extent the CPP-PP rain retrievals can be used to monitor the seasonal progression of the WAM and the precipitation characteristics at sub-daily scale. It was shown that both the accumulated precipitation and the seasonal progression of rainfall throughout the WAM has a good agreement with CMORPH, although CPP-PP retrieves higher rain amounts over the coastal region of West Africa. Using latitudinal Hovmüller diagrams, again a fair correspondence between CPP-PP and CMORPH was found, which is reflected by high correlation coefficients $(\sim 0.7)$ for both rain rate and rain occurrence frequency.

The daytime cycle of rainfall from CPP-PP shows distinctly different patterns for three different regions throughout the WAM, with a decrease in dynamical range in the vicinity of the ITCZ, a feature which is attributed to the occurrence of dynamically driven convective systems being dominant over convection forced through differential heating of the land surface. The dynamical range of the daytime rainfall cycle as retrieved from CPP-PP is larger than that from CMORPH. We speculate this to be both resulting from the better spatio-temporal resolution of the SEVIRI instrument, as well as from thermal infrared radiances being partly used by CMORPH, which likely smoothes the daytime precipitation signal, especially when cold anvils from convective systems are present. Another feature emerging from the comparison of the CPP-PP and CMORPH daytime cycles is that although CPP-PP has a larger dynamical range of daytime rainfall than $C M O R P H$, the absolute value of the respective percentiles are lower. On the other hand, it was pointed out that the absolute value of CMORPH daytime rainfall dynamical range likely is too high, due to the tendency of CMORPH to overestimate rainfall of convective systems over continental areas. 

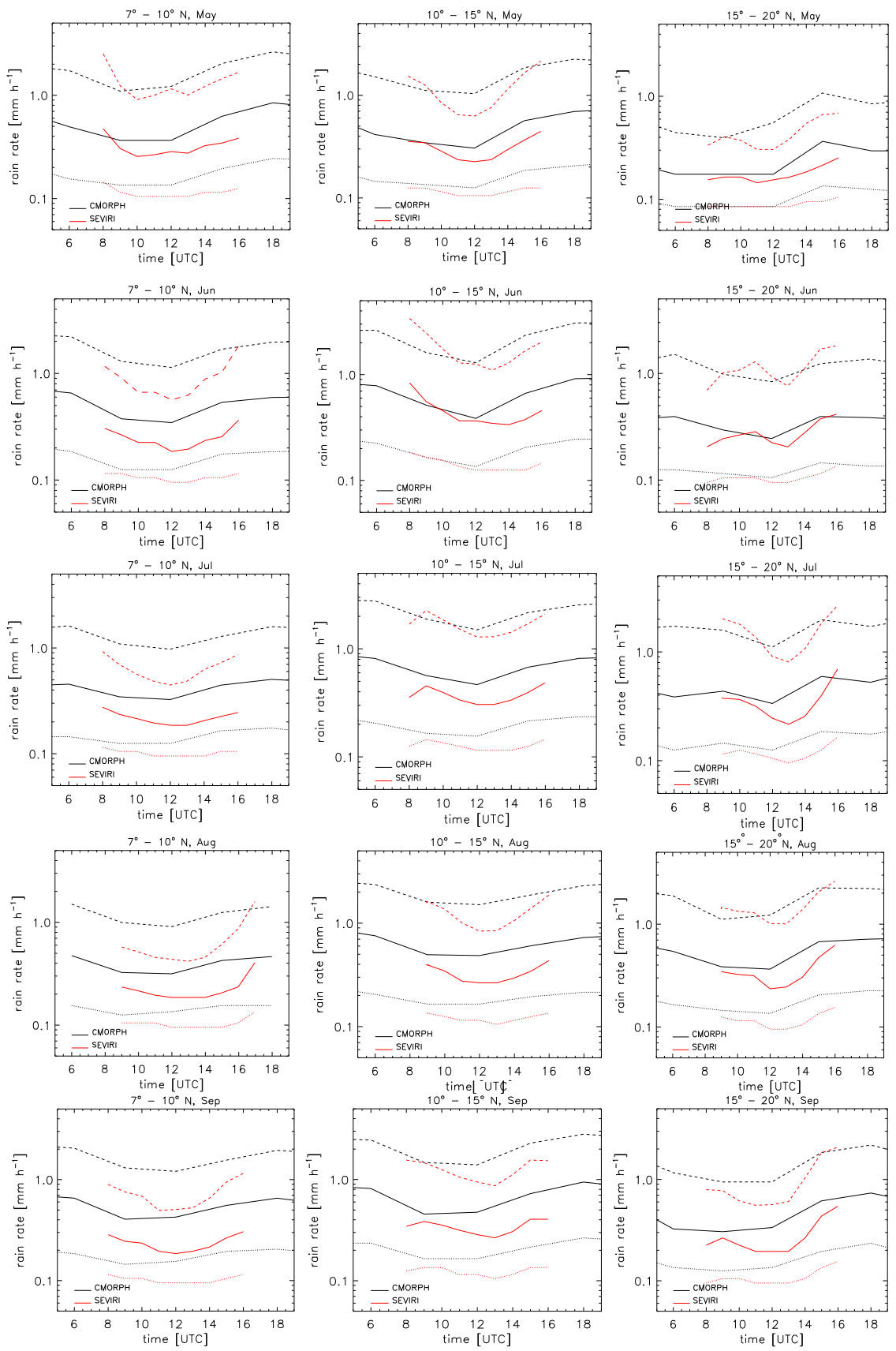

Fig. 9. (Black) CMORPH and (red) CPP-PP daytime cycle of rain rate (for values with $R>0.05 \mathrm{~mm} \mathrm{~h}^{-1}$ ) from May-September (average of 2005 and 2006) for (left column) $7^{\circ}-10^{\circ} \mathrm{N}$, (middle column) $10^{\circ}-15^{\circ} \mathrm{N}$, and (right column) $15^{\circ}-20^{\circ} \mathrm{N}$. Values were averaged over $10^{\circ} \mathrm{W}-10^{\circ} \mathrm{E}$, CPP-PP rain retrievals have been collected in hourly bins. The 25 th (dotted), 50th (solid), and 75 th (dashed) percentiles are shown.

The unprecented 15-min temporal resolution in combination with the $3 \times 3 \mathrm{~km}^{2}$ spatial sampling of SEVIRI makes it a well-suited instrument to monitor precipitation features, both at sub-daily and at seasonal scale. Over West Africa, about 40 rainfall retrievals per day can be performed for a single location, which makes SEVIRI a suitable instrument to monitor year-to-year changes in daytime precipitation patterns. In contrast, the TRMM satellite revisits the same location only once in $\sim 10$ days and a full diurnal cycle is captured once every 47 days, which necessitates at least several years of data to obtain substantial statistics. 
Without neglecting the differences between CPP-PPTRMM-PR and CPP-PP-CMORPH, the overall results show that the CPP-PP algorithm has a promising accuracy in retrieving rain rate and occurrence frequence over tropical areas. As already pointed out by Ebert et al. (2007) and Sapiano and Arkin (2009), it is difficult to assess "a best" rainfall retrieval algorithm, as each algorithm has its strengths and weaknesses over different climate regions, which are for the largest part imposed by instrumental constraints. For example, PMW rainfall observations relying on the emission of hydrometeors have problems over land surfaces, since both the intensity and heterogeneity of the surface background emission reduces the signal-to-noise ratio.

For the CPP-PP algorithm, its strengths exist in the use of retrieved cloud-top properties from SEVIRI to estimate rain rate, which is more physically based than e.g. the widely used cold cloud duration techniques developed in the 1970s and 1980s. In addition, the retrieved cloud-top properties are observed by the same instrument, which excludes the usage of merging and normalization procedures, such as necessary for CMORPH.

On the other hand, the availability of CPP-PP rainfall retrievals is currently limited to daytime only, due to its dependency on VIS/NIR reflectances. During nighttime, SEVIRI only provides observations from the water vapor $(6.2 \mu \mathrm{m}$ and $7.3 \mu \mathrm{m})$ and thermal infrared $(8.7 \mu \mathrm{m}-13.4 \mu \mathrm{m})$ spectral channels. These channels might be useful to continue our present daytime rainfall retrievals during the night. For example, Behrangi et al. (2009) showed that using all channels from $6.2 \mu \mathrm{m}-13.4 \mu \mathrm{m}$ improves the rainfall retrieval evaluation statistics compared to those for the $10.8 \mu \mathrm{m}$ channel only.

Another limitation of the present CPP-PP algorithm is that since in general precipitation occurs in thick clouds and the usage of passively observed reflectances implies that rain rate is estimated from cloud-top properties, hence no information from lower atmospheric layers is available. Especially in the tropics, a too high rain rate may be retrieved, due to a considerable amount of the precipitation at cloud base being evaporated before reaching the surface. This below-cloud evaporation fraction may add up to $50 \%$, depending on cloud base height, rain rate at cloud base, and the below-cloud relative humidity (Rosenfeld and Mintz, 1988). Implementation of a correction for below-cloud evaporation (e.g. Petty, 2001) is planned to be incorporated in future versions of CPP-PP.

Being operational since 2004, SEVIRI comprises a substantial statistical dataset to study the interaction between cloud-top properties, precipitation, and for example the large-scale dynamics or land surface characteristics (soil moisture, vegetation, etc.). These process studies are useful to evaluate among others the cloud, rainfall, and land surface-atmosphere interaction predictions of regional climate models (see e.g. the work of Greuell et al., 2010 and Roebeling and van Meijgaard, 2009).
Acknowledgements. This research was carried out within the Water Cycle Multi Mission Observation Strategy (WACMOS) project of the European Space Agency (ESA). TRMM-PR data was downloaded from the DAAC Data Pool at NASA Goddard Space and Flight Center (GSFC). CMORPH data was obtained from the Climate Prediction Center (CPC) website. The authors thank Jan Fokke Meirink (KNMI) for his useful comments to improve the manuscript. Finally, we acknowledge Theo Vischel, Marielle Gosset (Laboratoire d'étude des Transferts en Hydrologie et Environnement, LTHE, Grenoble, France), and Marc Arjounin (L'Institut de Recherche pour le Développement, IRD, Mali) for providing the AMMA mesoscale sites rain gauge data.

Edited by: P. van Oevelen

\section{References}

Adler, R. F. and Negri, A. J.: Satellite infrared technique to estimate tropical convective and stratiform rainfall, J. Appl. Meteorol., 27, 30-71, 1988.

Ali, A., Lebel, T., and Amani, A.: Rainfall Estimation in the Sahel. Part I: Error function., J. Appl. Meteorol., 44, 1691-1706, doi:10.1175/JAM2304.1, 2005.

Arkin, P. A. and Meisner, B. N.: The relationship between largescale convective rainfall and cold cloud over the Western Hemisphere during 1982-1984, Mon. Wea. Rev., 115, 51-74, 1987.

Arkin, P. A. and Xie, P.: The Global Precipitation Climatology Project: First algorithm intercomparison project, B. Am. Meteorol. Soc., 75, 401-419, 1994.

Ba, M. B. and Gruber, A.: GOES multispectral rainfall algorithm (GMSRA), J. Appl. Meteorol., 40, 1500-1514, 2001.

Basu, B. K.: Diurnal variation in precipitation over India during the summer monsoon season: observed and model predicted, Mon. Wea. Rev., 135, 2155-2167, doi:10.1175/MWR3355.1, 2007.

Behrangi, A., Hsu, K.-L., Imam, B., Sorooshian, S., Huffman, G. J., and Kuligowski, R. J.: PERSIANN-MSA: A Precipitation Estimation Method from Satellite-Based Multispectral Analysis, J. Hydrometeorol., 10, 1414-1429, doi:10.1175/2009JHM1139.1, 2009.

Cook, K. H.: Generation of the African Easterly Jet and its role in determining West African precipitation, J. Clim., 12, 1165-1184, 1999.

Dai, A.: Global precipitation and thunderstorm frequencies, Part II: Diurnal variations., J. Climate, 14, 1112-1128, doi:10.1175/1520-0442(2001)014<1112:GPATFP > 2.0.CO;2, 2001.

De Haan, J. F., Bosma, P. B., and Hovenier, J. W.: The adding method for multiple scattering calculations of polarized light, Astron. Astrophys., 183, 371-391, 1987.

Diongue, A., Lafore, J. -P., Redelsperger, J. -L., and Roca, R.: Numerical study of a Sahelian synoptic weather system: Initiation and mature stages of convection and its interactions with the large-scale dynamics, Q. J. R. Meteorol. Soc., 128, 1899-1927, 2002.

Ebert, E. E., Janowiak, J. E., and Kidd, C.: Comparison of near-real-time precipitation estimates from satellite observations 
and numberical models, B. Am. Meteorol. Soc., 88, 47-64, doi:10.1175/BAMS-88-1-47, 2007.

Fink, A. H. and Reiner, A.: Spatiotemporal variability of the relation between African Easterly Waves and West African Squall Lines in 1998 and 1999, J. Geophys. Res., 108, 4332-4348, doi:10.1029/2002JD002816, 2003.

Greuell, J. W., van Meijgaard, E., and Clerbaux, N.: Evaluation of model predicted top-of-atmosphere radiation and cloud parameters over Africa with observations from GERB and SEVIRI, J. Climate, submitted, 2010.

Greuell,W. and Roebeling, R. A.: Toward a standard procedure for validation of satellite-derived cloud liquid water path: A study with SEVIRI data, J. Appl. Meteorol. Clim., 48, 1575-1590, doi:10.1175/2009JAMC2112.1, 2009.

Hagos, S. M. and Cook, K. H.: Dynamics of the West African Monsoon jump, J. Clim., 20, 5264-5284, doi:10.1175/J2007CLI1533.1, 2007.

Huffman, G. J., Adler, R. F., Morrissey, M. M., Bolvin, D. T., Curtis, S., Joyce, R., McGavock, B., and Susskind, J.: Global Precipitation at One-Degree Daily Resolution from Multisatellite Observations, J. Hydrometeor., 2, 36-50, doi:10.1175/15257541(2001)002<0036:GPAODD>2.0.CO;2, 2001.

Huffman, G. J., Adler, R. F., Bolvin, D. T., Gu, G., Nelkin, E. J., Bowman, K. P., Hong, Y., Stocker, E. F., and Wolff, D. B.: The TRMM Multisatellite Precipitation Analysis (TMPA): QuasiGlobal, Multiyear, Combined-Sensor Precipitation Estimates at Fine Scales, J. Hydrometeor., 8, 38-54, doi:10.1175/JHM560.1, 2007.

Iguchi, T., Kozu, T., Meneghini, R., Awaka, J., and Okamoto, K.: Rain profiling algorithm for TRMM precipitation radar data, J. Appl. Meteorol., 39, 2038-2052, 2000.

Janicot, S., Thorncroft, C. D., Ali, A., Asencio, N., Berry, G., Bock, O., Bourles, B., Caniaux, G., Chauvin, F., Deme, A., Kergoat, L., Lafore, J.-P., Lavaysse, C., Lebel, T., Marticorena, B., Mounier, F., Nedelec, P., Redelsperger, J.-L., Ravegnani, F., Reeves, C. E., Roca, R., de Rosnay, P., Schlager, H., Sultan, B., Tomasini, M., Ulanovsky, A., and ACMAD forecasters team: Large-scale overview of the summer monsoon over West Africa during the AMMA field experiment in 2006, Ann. Geophys., 26, 2569-2595, doi:10.5194/angeo-26-2569-2008, 2008.

Jobard, I., Chopin, F., Berges, J.C., and Roca, R.: An intercomparison of 10-day precipitation satellite products during West African monsoon, Int. J. Remote Sens, doi::10.1080/01431161003698286, in press, 2010.

Joyce, R. J., Janowiak, J. E., Arkin, P. A., and Xie, P.: CMORPH: A Method that Produces Global Precipitation Estimates from Passive Microwave and Infrared Data at High Spatial and Temporal Resolution, J. Hydrometeor., 5, 487-503, doi:10.1175/15257541(2004)005<0487:CAMTPG>2.0.CO;2, 2004.

Kidd, C.: Satellite rainfall climatology: a review, Int. J. Climatol., 21, 1041-1066, doi:10.1002/joc.365, 2001.

Kidd, C., and Levizzani, V.: Status if satellite precipitation retrievals, Hydrol. Earth Syst. Sci. Discuss., 7, 8157-8177, doi:10.5194/hessd-7-8157-2010, 2010.

Kummerow, C., Barnes, W., Kozu, T., Shuie, J., and Simpson, J.: The Tropical Rainfall Measuring Mission (TRMM) sensor package, J. Atmos. Ocean. Technol., 15, 809-817, 1998.

Liao, L. and Meneghini, R.: Validation of TRMM precipitation radar through comparison of its multiyear measurements with ground-based radar, J. Appl. Meteorol. Clim., 48, 804-817, doi:10.1175/2008JAMC1974.1, 2009.

Mecikalski, J. R. and Bedka, K. M.: Forecasting convective initiation by monitoring the evolution of moving cumulus in daytime GOES imagery, Mon. Weather Rev., 134, 49-78, 2006.

Mohr, K. I.: Interannual, monthly, and regional variability in the wet season diurnal cycle of precipitation in Sub-Saharan Africa, J. Climate, 17, 2441-2453, 2004.

Negri, A. J. and Adler, R. F.: An intercomparison of three satellite infrared rainfall techniques over Japan and surrounding waters, J. Appl. Meteorol., 32, 357-373, 1993.

Negri, A. J., Adler, R. F., and Wetzel, P. J.: Satellite rain estimation: An analysis of the Griffith-Woodley technique, J. Clim. Appl. Meteorol., 26, 1565-1576, 1984.

Nicholson, S. E., Tucker, C. J., and Ba, M. B.: Desertification, drought, and surface vegetation: an example from the West African Sahel, B. Am. Meteorol. Soc., 79, 815-829, 1998.

Nicholson, S. E., Some, B., McCollum, J., Nelkin, E., Klotter, D., Berte, Y., Diallo, B. M., Gaye, I., Kpabeba, G., Ndiaye, O., Noukpozounkou, J. N., Tanu, M. M., Thiam, A., Toure, A. A., and Traore, A. K.: Validation of TRMM and other rainfall estimates with a high-density gauge dataset for West Africa. Part II: Validation of TRMM rainfall products, J. Appl. Meteorol., 42, 1355-1368, doi:10.1175/15200450(2003)042<1355:VOTAOR > 2.0.CO;2, 2003.

Petty, G. W., 2001: Physical and Microwave Radiative Properties of Precipitating Clouds. Part II: A Parametric 1D RainCloud Model for Use in Microwave Radiative Transfer Simulations, J. Appl. Meteor., 40, 2115-2129. doi:10.1175/15200450(2001)040<2115:PAMRPO > 2.0.CO;2

Pruppacher, H. R. and Klett, J. D.: Microphysics of Clouds and Precipitation, 2nd rev. and enl. ed., Kluwer Academic Publishers, Dordrecht, The Netherlands, 1997.

Ramel, R., Gallée, H., and Messager, C.: On the northward shift of the West African monsoon, Clim. Dynam., 26, 429-440, doi:10.1007/s00382-005-0093-5, 2006.

Redelsperger, J., Thorncroft, C. D., Diedhiou, A., Lebel, T., Parker, D. J., and Polcher, J.: African Monsoon Multidisciplinary Analysis: an international research project and field campaign, B. Am. Meteorol. Soc., 87, 1739-1746, doi:10.1175/BAMS-8712-1739, 2006.

Roca, R., Chambon, P., Jobard, I., Kirstetter, P.-E., Gosset, M., and Bergés, J. C.: Comparing satellite and surface rainfall products over West Africa at meteorologically relevant scales during the AMMA campaign using error estimates, J. Appl. Meteorol. Climatol., 49, 715-731, 2010.

Roebeling, R. A. and Holleman, I.: Validation of rain rate retrievals from SEVIRI using weather radar observations, J. Geophys. Res., 114, D21202, doi:10.1029/2009JD012102, 2009.

Roebeling, R. A. and van Meijgaard, E.: Evaluation of the Daylight Cycle of Model-Predicted Cloud Amount and Condensed Water Path over Europe with Observations from MSG SEVIRI, J. Clim., 22, 1749-1766, doi:10.1175/2008JCLI2391.1

Roebeling, R. A., Feijt, A. J., and Stammes, P.: Cloud property retrievals for climate monitoring: implications of differences between Spinning Enhanced Visible and Infrared Imager (SEVIRI) on Meteosat-8 and Advanced Very High Resolution Radiometer (AVHRR) on NOAA-17, J. Geophys. Res., 111, D20210, doi:10.1029/2005JD006990, 2006. 
Rosenfeld, D. and Mintz, Y.: Evaporation of rain falling from convective clouds as derived from radar measurements, J. Appl. Meteorol., 27, 209-215, doi:10.1175/15200450(1988)027<0209:EORFFC>2.0.CO;2, 1988.

Rudolf, B.: Management and analysis of precipitation data on a routine basis, Proc. Int. WMO/IAHS/ETH Symp. on Precipitation and Evaporation, Bratislava, Slovakia, Slovak Hydrometeorology Institute, 69-76, 1993.

Sapiano, M. R. P. and Arkin, P. A.: An intercomparison and validation of high-resolution satellite precipitation estimates with 3-hourly gauge data, J. Hydrometeorol., 10, 149-166, doi:10.1175/2008JHM1052.1, 2009.

Schutgens, N. A. J. and Roebeling, R. A.: Validating the validation: The influence of liquid water distribution in clouds on the intercomparison of satellite and surface observations, J. Atmos. Ocean. Technol., 26, 1457-1474 doi:10.1175/2009JTECHA1226.1.

Stammes, P.: Spectral radiance modelling in the UV-visible range, in: IRS 2000: Current Problems in Atmospheric Radiation, edited by: Smith, W. L. and Timofeyev, Y. M., A. Deepak, Hampton, VA, 385-388, 2001.

Sultan, B. and Janicot, S.: The West African monsoon dynamics. Part II: The "preonset" and "onset" of the summer monsoon, J. Climate, 16, 3407-3427, doi:10.1175/15200442(2003)016<3407:TWAMDP>2.0.CO;2, 2003.

Sultan, B., Janicot, S., and Drobinski, P.: Characterization of the diurnal cycle of the West African monsoon around the monsoon onset, J. Climate, 20, 4014-4032, doi:10.1175/ JCLI4218.1, 2007.
Taylor, C. M. and Ellis, R. J.: Satellite detection of soil moisture impacts on convection at the mesoscale, Geophys. Res. Lett., 33, doi:10.1029/2005GL025252, 2006.

Taylor, C. M., Parker, D. J., and Harris, P. P.: An observational case study of mesoscale atmospheric circulations induced by soil moisture, Geophys. Res. Lett., 34, L15801, doi:10.1029/ 2007GL030572, 2007.

Tian, Y., Peters-Lidard, C. D., Adler, R. F., Kubota, T., and Ushio, T.: Evaluation of GSMaP precipitation estimates over the Contiguous United States, J. Hydrometeorol., 11, 566-574, doi:10.1175/2009JHM1190.1, 2010.

Wentz, F. J. and Spencer, R. W.: SSM/I rain retrievals within a unified all-weather ocean algorithm, J. Atmos. Sci., 55, 1613-1627, 1998.

Wolters, E. L. A., Roebeling, R. A., and Feijt, A. J.: Evaluation of cloud phase retrieval methods for SEVIRI onboard Meteosat-8 using ground-based lidar and cloud radar data, J. Appl. Meteorol. Clim., 47, 1723-1738, doi:10.1175/2007JAMC1591.1, 2008.

Wolters, E. L. A., Deneke, H. M., van den Hurk, B. J. J. M., Meirink, J. F., and Roebeling, R. A.: Broken and inhomogeneous cloud impact on satellite cloud particle effective radius and cloud-phase retrievals, J. Geophys. Res., 115, D10214, doi:10.1029/2009JD012205, 2010.

Yang, S. and Smith, E. A.: Mechanisms for diurnal variability of global tropical rainfall observed from TRMM, J. Climate, 19, 5190-5226, doi:10.1175/JCLI3883.1, 2006.

Zinner, T., Mannstein, H., and Tafferner, A.: Cb-TRAM: Tracking and monitoring severe convection from onset over rapid development to mature phase using multi-channel Meteosat8 SEVIRI data, Meteorol. Atmos. Phys., 101, 191-210, doi:10.1007/s00703-008-0290-y, 2008. 